\title{
Impacts of Climatic Variation and Human Activity on Runoff in Western China
}

\author{
Yinge Liu ${ }^{1,2, *}$, Keke Yu ${ }^{1,2}$, Yaqian Zhao ${ }^{3,4}$ (D) and Jiangchuan Bao ${ }^{2}$ \\ 1 Key Laboratory of Disaster Monitoring and Mechanism Simulating in Shaanxi Province, Baoji 721013, China; \\ yukezan2005@163.com \\ 2 College of Geography and Environment, Baoji University of Arts and Sciences, Baoji 721013, China; \\ bjc18428072995@163.com \\ 3 State Key Laboratory of Eco-Hydraulics in Northwest Arid Region, Xi'an University of Technology, \\ Xi'an 710048, China; yaqian.zhao@ucd.ie \\ 4 UCD Dooge Centre for Water Resources Research, School of Civil Engineering, University College Dublin, \\ Belfield, Dublin 4, Ireland \\ * Correspondence: liuyg@lzb.ac.cn
}

Citation: Liu, Y.; Yu, K.; Zhao, Y.; Bao, J. Impacts of Climatic Variation and Human Activity on Runoff in Western China. Sustainability 2022, 14, 942. https://doi.org/10.3390/ su14020942

Academic Editor: Tommaso Caloiero

Received: 22 November 2021

Accepted: 9 January 2022

Published: 14 January 2022

Publisher's Note: MDPI stays neutral with regard to jurisdictional claims in published maps and institutional affiliations.

Copyright: (C) 2022 by the authors. Licensee MDPI, Basel, Switzerland. This article is an open access article distributed under the terms and conditions of the Creative Commons Attribution (CC BY) license (https:// creativecommons.org/licenses/by/ $4.0 /)$.

\begin{abstract}
Hydrological cycle is sensitively affected by climatic variation and human activity. Taking the upper- and middle-stream of the Weihe River in western China as an example, using multiple meteorological and hydrological elements, as well as land-use/land-cover change (LUCC) data, we constructed a sensitivity model of runoff to climatic elements and human activities based on the hydro-thermal coupling equilibrium equation, while a cumulative slope was used to establish a comprehensive estimation model for the contributions of climatic variation and human activities to the changes of runoff. The results showed that the above function model established could be well applied to quantitatively study the elasticity of runoff's response to climatic variation and human activities. It was found that the annual average precipitation, evaporation, wind velocity, sunshine hours, relative humidity and runoff showed decreasing trends and that temperature increased. While in the hydrological cycle, precipitation and relative humidity had a non-linear positive driving effect on runoff, while temperature, evaporation, sunshine hours, wind velocity, and land-use/land-cover change (LUCC) have non-linearly negatively driven the variation of runoff. Moreover, runoff has a strong sensitive response to precipitation, evaporation and LUCC. In areas with strong human activities, the sensitivity of runoff to climatic change was decreasing, and runoff has a greater elastic response to underlying surface parameters. In addition, the analysis showed that the abrupt years of climate and runoff changes in the Weihe River Basin were 1970, 1985 and 1993. Before 1985, the contribution rate of climatic variation to runoff was $68.3 \%$, being greater than that of human activities to runoff, and then the contribution rates of human activities to runoff reached $75.1 \%$. The impact of natural climate on runoff was weakened, and the effect of human activities on runoff reduction increased. Under 30 hypothetical climatic scenarios, the evaluation of runoff in the future showed that the runoff in the Weihe River Basin will be greatly reduced, and the reduction will be more significant during the flood season. Comparing the geographically fragile environments and intense human activities, it was believed that climatic variation had a dramatic effect on driving the water cycle of precipitation and evaporation and affected regional water balance and water distribution, while human activities had driven the hydrological processes of the underlying surface, thus becoming the main factors in the reduction of runoff. This study provided scientific tools for regional climate change and water resources assessment.
\end{abstract}

Keywords: climate elements; runoff; sensitivity and contribution; response mechanism

\section{Introduction}

The hydrological cycle is an important material and energy cycle in the earth system, which was affected by many factors [1,2]. Among them, climatic variation and human 
activities have the most significant influences [3,4]. Natural evolution and human activities jointly drive global changes on various scales; in particular, climatic variation can affect the water cycle process, runoff and regional water balance by influencing precipitation and evaporation in a watershed [5-7]. From the IPCC fifth assessment report (IPCC, 2013), the global average surface temperature rose by $0.85{ }^{\circ} \mathrm{C}$ during the period of $1880-2012$, and the increasing rate from 1951 to 2012 was twice as fast as that since 1880. Human activities such as agricultural irrigation, industrial water use and the construction of reservoirs are already changing the hydrological cycle [8,9]. In the context of global climate, the distribution of water resources has been temporally and spatially altered by the comprehensive effects of human activities to a certain extent [10-12]. Therefore, exploring the influences of climatic variation on the hydrological cycles has become one of the current research hotspots. In recent years, scholars from all over the world have performed a large number of studies on the causes of river runoff and the evaluation of the impact of climatic variation on different scales, such as global, regional and watershed. The results from the literature showed that, due to the reduced precipitation and increased evaporation, runoff in some regions was reduced to a certain extent $[13,14]$. In terms of the attribution analysis of runoff change and the assessment of the impact of climate change and human activities on runoff changes, there were mainly two methods: model-simulation methods and water-balance methods based on the Budyko hypothesis, which were applied to carry out research on changes in runoff in specific watersheds $[15,16]$. For example, for the mutual response relationship between the hydrological cycle and climatic change, Ma et al. [17] and Yang et al. [18] used various statistics, models and experimental methods to study the elasticity of river runoff to climatic variation. Gao et al. [19] and Markovich et al. [20] studied the influence of land use on runoff using hydrological models and multiple regressions. Yin et al. [21] used the SWAT model to study the response of water yield to climate in northern China and believed that water yield was more sensitive to climate change. Guo et al. [22], Wang et al. [23] and Kong et al. [24] studied the impact of climate change and human activities on runoff using statistical models and reanalyzed data. They suggested that runoff was strongly affected by climatic variation and human activities and differed in different regions. Although the above-mentioned studies have achieved remarkable results, there is still significant uncertainty and limitations on the influences of climatic variation and human activities on runoff on global and regional scales. Moreover, there have been many studies on the contribution of climate variation to runoff from single meteorological elements, and different research methods also have certain limitations. The model simulation method has a certain mechanism explanation, but the uncertainty of the model structure and parameters, and the complexity of the relationship among topography, soil, vegetation and climate in the basin, etc., affected the range of the model response and the differences of the simulation results. Compared with the traditional mathematical statistics empirical method, the water-balance method based on Budyko's hydro-thermal coupling balance theory has obvious physical meaning, and the calculation process was relatively simple, and the parameters were easier to obtain. It has been widely used in the attribution of runoff changes in watersheds. However, there were still few studies on the attribution of multiple meteorological and hydrological factors to runoff changes using the water-heat coupled balance equation based on Budyko's hypothesis. Quantitative studies on how to decompose the sensitive contribution of climate change and human activities to runoff have represented the current research trend. More recently, the existing research seems to focus on how to deeply understand the interrelationships and mechanisms between climatic variation and the natural environment, as well as the hydrological cycle. The Penman-Monteith method was suitable for the calculation of potential evapotranspiration in different climate types and for studies of the impact of climatic change on the water cycle. Therefore, we can try to use the modified Penman-Monteith evaporation model to derive the elastic coefficients of various meteorological elements and human activities on runoff and to further carry out quantitative research on the influence of multiple factors 
(i.e., temperature, solar radiation, wind speed, relative humidity and underlying surface parameters) on runoff changes.

Taking the upper- and middle-stream of the Weihe River in western China as an example, this study mainly focused on the influences of multiple factors on runoff, while the relationships between runoff and climatic variation and human activities were further studied. Weihe River Basin has a semi-arid climate with annual precipitation of 400-600 mm, temperature of $6.1-10.8{ }^{\circ} \mathrm{C}$, evaporation of $1130-395 \mathrm{~mm}$, sunshine hours of 2001-2419 h and runoff of 16-32.5 $\times 10^{8} \mathrm{~m}^{3}$, and economic development and high population density, while water resources were sensitively influenced by human activities and global climatic variation. Therefore, by using multiple meteorological and hydrological elements as well as land-use/land-cover change (LUCC) data, we constructed a sensitivity model of runoff to climatic elements and human activities based on the hydro-thermal coupling equilibrium equation. As such, we analyzed the relationship between multi-factors and runoff changes and quantitatively studied the elasticity of runoff's response to climatic variation and human activities. Accordingly, the contribution rate of climatic variation and human activities to runoff was decomposed and evaluated. At the same time, the response mechanism of hydrological processes to climatic elements and human activities was discussed. It is expected that this study can provide the basis for regional environmental, climate and water resource management and assessment.

\section{Materials and Methods}

\subsection{Meteorological and Hydrological Data}

The upper- and middle-stream of the Weihe River in western China is located between $33^{\circ} 43^{\prime} \mathrm{N}-36^{\circ} 32^{\prime} \mathrm{N}$ and $109^{\circ} 1^{\prime}-103^{\circ} 31^{\prime} \mathrm{E}$ with large terrain altitude differences. This region has a semi-arid climate and significant changes of runoff. In this area, the water resources are sensitively influenced by human activities and global climatic variation. In this study, the daily observation meteorological data (from 1960 to 2017), including average temperature, precipitation, evaporation, wind speed, relative humidity, and sunshine hours, were obtained from the National Meteorological Information Center (NMIC) in China Meteorological Administration (CMA), while the runoff was used as an indicator of hydrological changes. Runoff data (from 1960 to 2015) were gained from hydrological stations. The monthly meteorological data and hydrological data were obtained from the daily data, while the annual data were obtained from the monthly data. Data missing rate was less than $1 \%$. The missing data were interpolated using a 10-year moving average. The data had been tested and revised and were consistent and reliable for studying climatic variation and hydrological impacts. To increase the reliability of the research results, 28 evenly distributed weather stations were selected, and the representative six hydrological stations in Weiyuan (SM1), Wushan (SM2), Beidao (SM3), Linjiacun (SM4), Yimen (SM5) and Qianhe (SM6) were selected (Figure 1). The distributions of soil type and land-use type in the Weihe River Basin were shown in Figure 2. There were a total of 19 soil types, including artificial fatness soil (AFS), clayed chestnut soil (CCS), gleaming black soil (GBS), simply cultivate black soil (SCBS), saturated embryonic soil (SES), bleached highly active leached soil (BHALS), calcium-accumulated highly active leached soil (CHALS), gleaming embryonic soil (GES), simply cultivate chernozem soil (SCC), saturated loose rock soil (SLRS), calcium accumulation chernozem (CAC), calcareous loose rock soil (CLRS), gleed highly active leached soil (GHALS), simply cultivate gray soil (SCGS), unsaturated prototype soil (UPS), calcareous alluvial soil (CAS), calcareous prototype soil (CPS), man-made accumulation soil (MAS), and simple cultivation of highly active leached soil (SCHALS). There were 8 types of land use, including agricultural land (AGRL), forest (FRST), pasture land (PAST), waters (WATR), urban land (UBRN), rural land (URLD), traffic construction (UTRN) and bare land (BARR) (Table 1). 


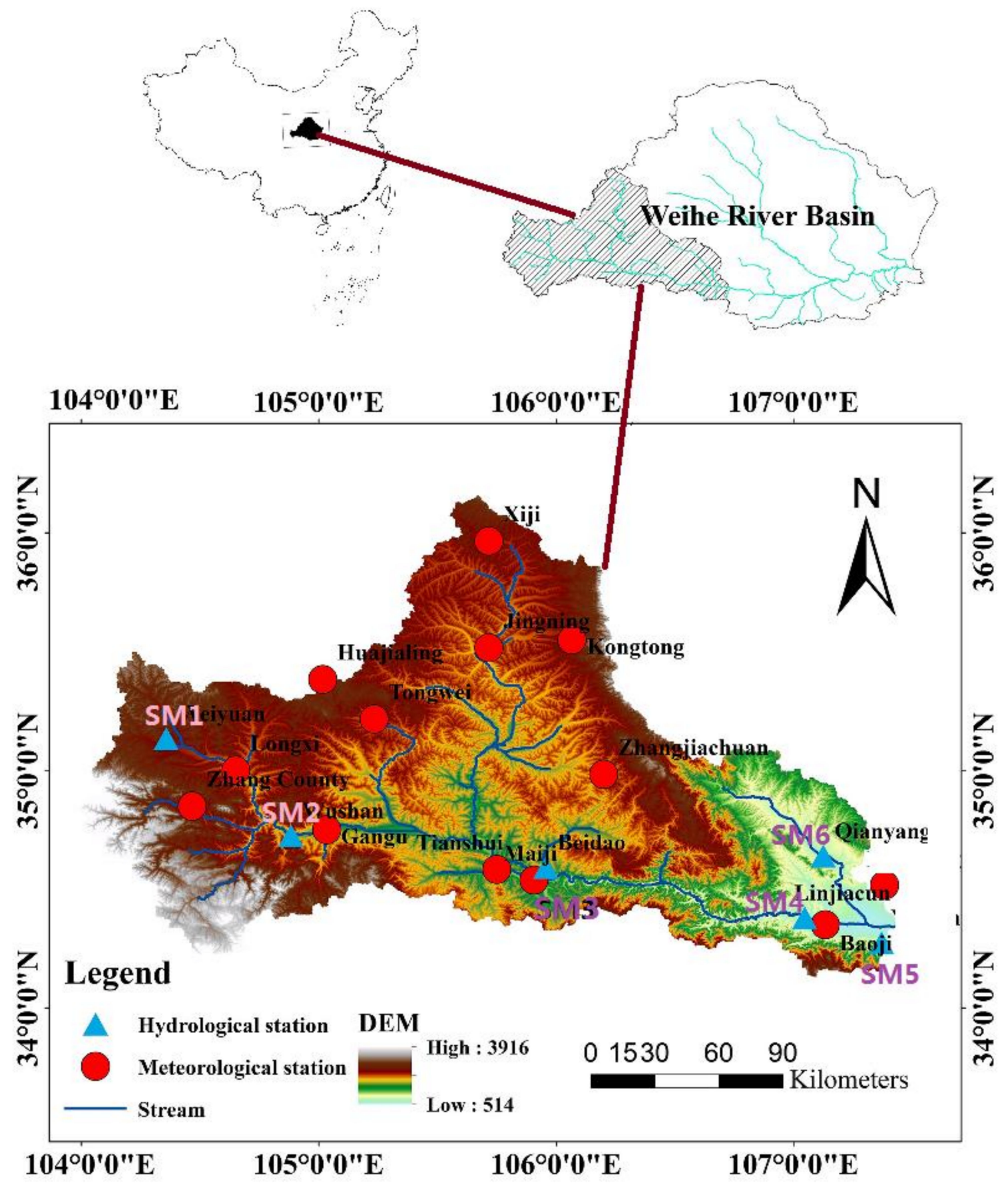

Figure 1. Distribution of meteorological and hydrological stations in the upper- and mid-stream of the Weihe River Basin in western China. 

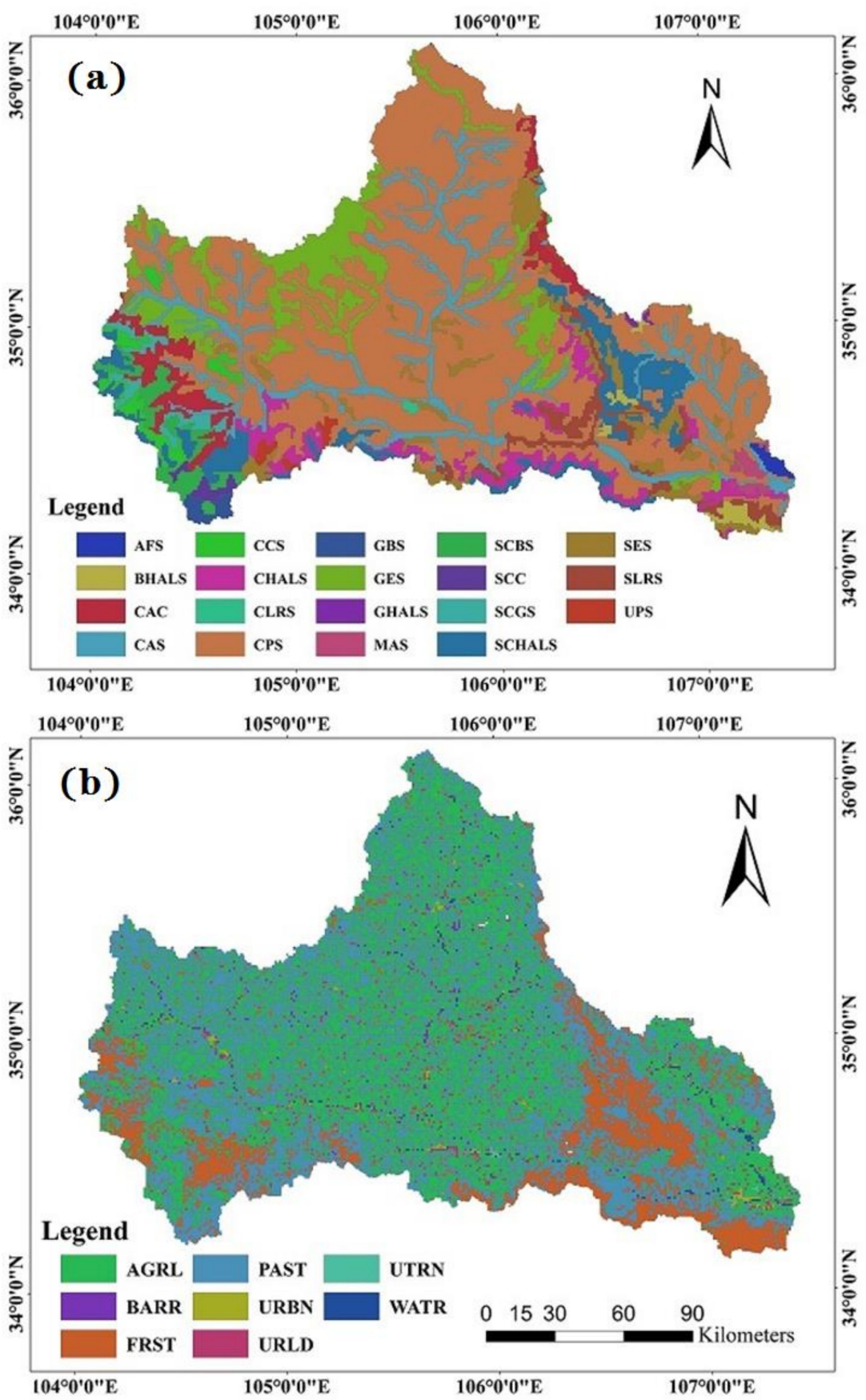

Figure 2. Distribution of (a) soil type and (b) land-use type.

Table 1. The overall land use in the watershed (Unit: $10^{5} \mathrm{ha}$ ).

\begin{tabular}{cccccccc}
\hline AGRL & FRST & PAST & WATR & UBRN & URLD & UTRN & BARR \\
\hline 13.817 & 3.838 & 12.384 & 0.195 & 0.119 & 0.636 & 0.045 & 0.112 \\
\hline
\end{tabular}

\subsection{Methods}

2.2.1. Climate Diagnosis Method and Calculation of the Sensitivity Coefficient

Climate and hydrological elements have continuous fluctuations over time. Therefore, the least square method was used to calculate the tendency rate. The climate and hydrological change trends were analyzed by calculating anomalies and cumulative anomalies, while the sliding $t$-test method (S-T) was used to analyze the abrupt points of climate 
and hydrological cycles. Correlation analysis method was used to assess the relationship between climatic elements and hydrological elements.

In the calculation, the elasticity coefficient was defined as the response intensity of runoff to climate. The IPCC provided a definition of sensitivity, which can be used to estimate the sensitivity of runoff to a single climate element [25]. However, the water cycle was affected by many factors. Therefore, based on the hydro-thermal coupling equilibrium equation, a sensitivity model of runoff to climatic elements and human activities was established. Combining the equilibrium equation of water and heat, the total differential equations for the sensitivity of runoff to temperature, precipitation, evaporation, wind velocity, sunshine hours, relative humidity and LUCC were derived, and the elasticity coefficient was obtained. The calculation steps of the sensitivity coefficient were as follows.

Firstly, according to Budyko [26] and the derived water-heat coupling balance equation with evapotranspiration calculation (Penman-Monteith model from World Food and Agriculture Organization (FAO)) [27], evaporation (e) was proposed as a function of potential evaporation $\left(e_{p e}\right)$, precipitation $(p)$ and human activity $(h)$ :

$$
e=p e_{p e} /\left(p^{h}+e_{p e}{ }^{h}\right)^{1 / h}
$$

Then, according to the multi-year average water balance relationship of the basin, runoff $(r)$ was derived as a function of potential evaporation $\left(e_{p e}\right)$, precipitation $(p)$ and human activity $(h)$ :

$$
r=p-e=f\left(p, e_{p e}, h\right)
$$

Based on the modified Penman-Monteith method, the potential evaporation $\left(e_{p e}\right)$ was presented as the total differential of solar radiation $(s)$, temperature $(t)$, wind velocity $(w)$ and relative humidity $(m)$, showing as follows:

$$
d e_{p e} \approx \frac{\partial e_{p e}}{\partial s} d s+\frac{\partial e_{p e}}{\partial t} d t+\frac{\partial e_{p e}}{\partial w} d w+\frac{\partial e_{p e}}{\partial m} d m
$$

Combined with Budyko's water-heat coupling balance equation, the full differential equation of climate and human activities on runoff changes was derived as follows:

$$
\frac{d r}{r}=s c_{p} \frac{d p}{p}+s c_{t} \frac{d t}{t}+s c_{e} \frac{d e_{p e}}{e_{p e}}+s c_{h} \frac{d h}{h}+s c_{s} \frac{d s}{s}+s c_{w} \frac{d w}{w}+s c_{m} \frac{d m}{m}
$$

where the derivative equations for the sensitivity of runoff to temperature, precipitation, evaporation, wind velocity, sunshine hours, relative humidity and LUCC were derived, while the elasticity coefficient was obtained as follows:

$$
\begin{aligned}
& s c_{p}=\frac{\partial f}{\partial p} \frac{\Delta p}{\Delta r}, s c_{e}=\frac{\partial f}{\partial p} \frac{\Delta e}{\Delta r}, s c_{h}=\frac{\partial f}{\partial p} \frac{\Delta h}{\Delta r}, s c_{t}=\frac{\partial e_{p e}}{\partial s} \frac{\Delta t}{\Delta r}, s \mathcal{C}_{s}=\frac{\partial e_{p e}}{\partial s} \frac{\Delta s}{\Delta r}, s c_{w}=\frac{\partial e_{p e}}{\partial w} \frac{\Delta w}{\Delta r}, \\
& s c_{m}=\frac{\partial e_{p e}}{\partial m} \frac{\Delta m}{\Delta r}, s c^{\prime}{ }_{t}=s c_{e} \frac{\partial e_{p e}}{\partial s} \frac{\Delta t}{\Delta e}, s c^{\prime}{ }_{s}=s c_{e} \frac{\partial e_{p e}}{\partial s} \frac{\Delta s}{\Delta e},{ }^{\prime}, s c^{\prime}{ }_{w}=s c_{e} \frac{\partial e_{p e}}{\partial w} \frac{\Delta w}{\Delta e}, s c^{\prime}{ }_{m}=s c_{e} \frac{\partial e_{p e}}{\partial m} \frac{\Delta m}{\Delta e}
\end{aligned}
$$

where $s c_{p}, s c_{e}, s c_{h}, s c_{t}, s c_{s}, s c_{w}$ and $s c_{m}$ represented the single-factor elastic coefficients of precipitation, evaporation, LUCC, temperature, sunshine hours, wind velocity and relative humidity, respectively. $s c^{\prime}{ }_{p}, s c^{\prime}{ }_{e}, s c^{\prime}{ }_{h}, s c^{\prime}{ }_{1}, s c^{\prime}{ }_{s}, s c^{\prime}{ }_{w}$ and $s c^{\prime}{ }_{m}$ represented the multifactor comprehensive elastic coefficients of precipitation, evaporation, LUCC, temperature, sunshine hours, wind velocity and relative humidity, respectively, and $\Delta p, \Delta r, \Delta h, \Delta e, \Delta t, \Delta s$, $\Delta w$ and $\Delta m$ were variables of precipitation, runoff, LUCC, evaporation, temperature, sunshine hours, wind velocity and relative humidity, respectively. Herein, $e_{p e}$ was calculated using the function from the literature [28].

Among them, the larger the value of the sensitivity coefficient was, the greater the response runoff to climatic elements and human activities was, and vice versa. Positive values indicated positive correlation sensitivity, while negative values implied anti-correlation sensitivity. 


\subsubsection{Estimation Method for the Contribution of Elements to Runoff}

Climatic variation and human activity can significantly influence runoff in the hydrological cycle. Herein, a cumulative slope was used to study the contribution of climatic variation and human activities to the changes in runoff. Moreover, the meteorological and hydrological elements were standardized to eliminate the dimensional differences and to facilitate a comparison of runoff changes from different factors.

The calculation principles were as follows: The contribution of human activities and natural climatic variation to runoff varied for each period due to the different patterns of climatic variation before and after the year with abrupt changes (upward, abrupt and downward trends). Firstly, the cumulative anomalies of meteorological elements and runoff were calculated. Secondly, the mutation points of climatic variation over a period of time were determined. Finally, the linear fitting relationships of cumulative precipitation, cumulative potential evapotranspiration and cumulative runoff were established to calculate the slopes of the linear relationship between cumulative precipitation, cumulative evapotranspiration and cumulative runoff before and after the year with abrupt changes, respectively. The contribution of human activities to runoff was calculated by subtracting the estimated runoff from the actual runoff, while the contribution of climatic variation to runoff was calculated by subtracting the runoff in the benchmark period from the estimated runoff. Then the slope between the runoff and precipitation was used to estimate the runoff for each period. The 30-year average was used as the runoff benchmark to assess the influence of climatic variation and human activities on runoff during each period. In addition, its variables were decomposed, and then the contribution rates were calculated according to the following procedures:

For a precipitation series $p$ and evaporation series $e$, the length of the series was $n$, then the cumulative precipitation anomaly $\sum P$ and the cumulative evaporation anomaly $\sum E$ were calculated as follows.

$$
\begin{gathered}
P=\sum_{i=1}^{n}\left(p_{i}-\frac{1}{n} \sum_{i=1}^{n} p_{i}\right) \\
E=\sum_{i=1}^{n}\left(e_{i}-\frac{1}{n} \sum_{i=1}^{n} e_{i}\right)
\end{gathered}
$$

The runoff $\left(R_{C P}\right)$ caused by precipitation and the runoff $\left(R_{C E}\right)$ caused by potential evapotranspiration were calculated as follows.

$$
\begin{aligned}
& R_{C P}=\alpha_{1} \sum P+\beta_{1} \\
& R_{C E}=\alpha_{2} \sum E+\beta_{2}
\end{aligned}
$$

where $\alpha_{1}$ was the linear regression coefficient of accumulated runoff and accumulated precipitation, and $\beta_{1}$ was a constant calculated from the established runoff and precipitation equation; $\alpha_{2}$ was the linear regression coefficient of accumulated runoff and accumulated evaporation, and $\beta_{2}$ was a constant calculated from the established linear regression equation between accumulated runoff and accumulated evaporation. The higher the temperature was, the greater of the amount of evaporation. Accordingly, the smaller of the runoff was. Therefore, the potential evaporation was used to assess the influence of evaporation on runoff.

The factors causing runoff changes can be decomposed into two parts, climatic variation and human activities. The impact of climatic elements on the hydrological cycle was mainly reflected in the impact of precipitation and temperature on runoff. The temperature was closely related to evaporation, so evaporation was used to reflect the impact of temperature on runoff. The total runoff change was composed of the runoff caused by precipitation $\left(R_{C P}\right)$, the runoff caused by evaporation $\left(R_{C E}\right)$, measured runoff $\left(R_{M}\right)$ and the runoff caused by human activities $\left(R_{H}\right)$. Among them, the contribution rate of precipitation 
to runoff $\left(\eta_{C P}\right)$, the contribution rate of evaporation to runoff $\left(\eta_{C E}\right)$ and the contribution rate of human activities to runoff $\left(\eta_{H}\right)$ were calculated as follows.

$$
\begin{gathered}
\eta_{C p}=R_{C P} /\left(R_{C P}+R_{C E}+R_{M}\right) \\
\eta_{C E}=R_{C E} /\left(R_{C P}+R_{C E}+R_{M}\right) \\
\eta_{H}=1-\eta_{C P}-\eta_{C E}
\end{gathered}
$$

The larger the positive value of $\eta_{C P}, \eta_{C E}$, and $\eta_{H}$ was, the greater the contribution of each element to the reduction of runoff was, and vice versa. The negative value indicated that the each element could cause an increase of runoff.

\section{Results}

\subsection{Climate and Hydrological Trends}

The average value of each element from 1980 to 2003 was used as the baseline background for evaluating climate change, while the 30-year average values of temperature, precipitation, evaporation, wind speed, humidity, sunshine hours and runoff were calculated, which was $7.2^{\circ} \mathrm{C}, 460.4 \mathrm{~mm}, 1375.9 \mathrm{~mm}, 2.25 \mathrm{~m} / \mathrm{s}, 62.6 \%, 2566.5 \mathrm{~h}, 19.05 \times 10^{8} \mathrm{~m}^{3}$, respectively. The anomalies of climatic and hydrological elements were calculated as shown in Figure 3. It showed that, from 1960 to 1984 , the temperature was a negative anomaly, and the average negative anomaly was $0.02{ }^{\circ} \mathrm{C}$ lower than the multi-year average, and then the temperature rose; the average positive anomaly was $0.85^{\circ} \mathrm{C}$ higher than the multi-year average. Before 1982, the precipitation fluctuated. The average positive anomaly was $16.42 \mathrm{~mm}$ higher than the multi-year average. Then the precipitation became negative, and the average negative anomaly was $41.93 \mathrm{~mm}$ lower than the multi-year average. Evaporation showed a fluctuating change. From 1960 to 1963, evaporation was positive and then it turned into a negative anomaly. From 1986 to 2001, evaporation was positive, and then it showed a decreasing trend. In each period mentioned above, evaporation increased by $95.24 \mathrm{~mm}$, decreased by $-58.2 \mathrm{~mm}$, increased by $71.99 \mathrm{~mm}$, and decreased by $-40.12 \mathrm{~mm}$, respectively. Before the $1970 \mathrm{~s}$, the wind speed decreased by $-0.15 \mathrm{~m} / \mathrm{s}$ compared with the annual average. Then it increased by $0.13 \mathrm{~m} / \mathrm{s}$ compared with the annual average. After 1982, it was negative and decreased by $-0.15 \mathrm{~m} / \mathrm{s}$ compared with the annual average. Before 1992, the number of sunshine hours fluctuated. Then it decreased, showing $7.45 \mathrm{~h}$ less than the annual average sunshine. Before 1986, the runoff was positive, increased by $6.55 \times 10^{8} \mathrm{~m}^{3}$ compared with the annual runoff. Then it decreased, showing $8.2 \times 10^{8} \mathrm{~m}^{3}$ less than the annual average runoff.

Overall, the annual average temperature increased at a rate of $0.35{ }^{\circ} \mathrm{C} / 10$ year and passed $99 \%$ reliability test, while precipitation, wind velocity, evaporation, sunshine hours, relative humidity and runoff showed decreasing trends with the rates of $-14.01 \mathrm{~mm} / 10$ year, $-1.42 \mathrm{~mm} / 10$ year, $-11.9 \mathrm{~h} / 10$ year, $-0.32 \% / 10$ year and $-4.67 \times 10^{8} \mathrm{~m}^{3} / 10$ year, respectively. Before 1985, the temperature slightly fluctuated, while after 1985, the temperature increased significantly. In most areas, the temperature was increasing, while the precipitation and relative humidity were decreasing. The changing rate in the west was higher than that in the northeast. The wind velocity in the east decreased more than that in the west, while the decrease in evaporation in the south was greater than in the north. The sunshine was decreasing, and the changing rate in the west was greater than that in the east. The runoff at each station also has a significant decreasing trend. In 1960-1966, the runoff increased and then decreased, and the runoff was steadily oscillating from 1972 to 1987. After 2000, there was a slight increase in the runoff. The increase of temperature and the decrease of precipitation have caused a decrease of runoff. The evaporation did not show an increasing trend with the increase of temperature but showed a decreasing trend. This may be caused by: (1) Although the increase of temperature was conducive to the increase of evaporation, the reduction of solar radiation and wind speed led to a reduction of evaporation; (2) As a result of the combined effect, the evaporation in the upper reaches of the Weihe River showed a decreasing trend, resulting in a reduction of 
runoff; (3) The spatial difference of the change rate of each element was related to the geographical environment and human activities, which were more intense in the east than that in the west, while environmental changes were also greater. Therefore, the changes in climate and hydrological elements showed a temporal and spatial difference.
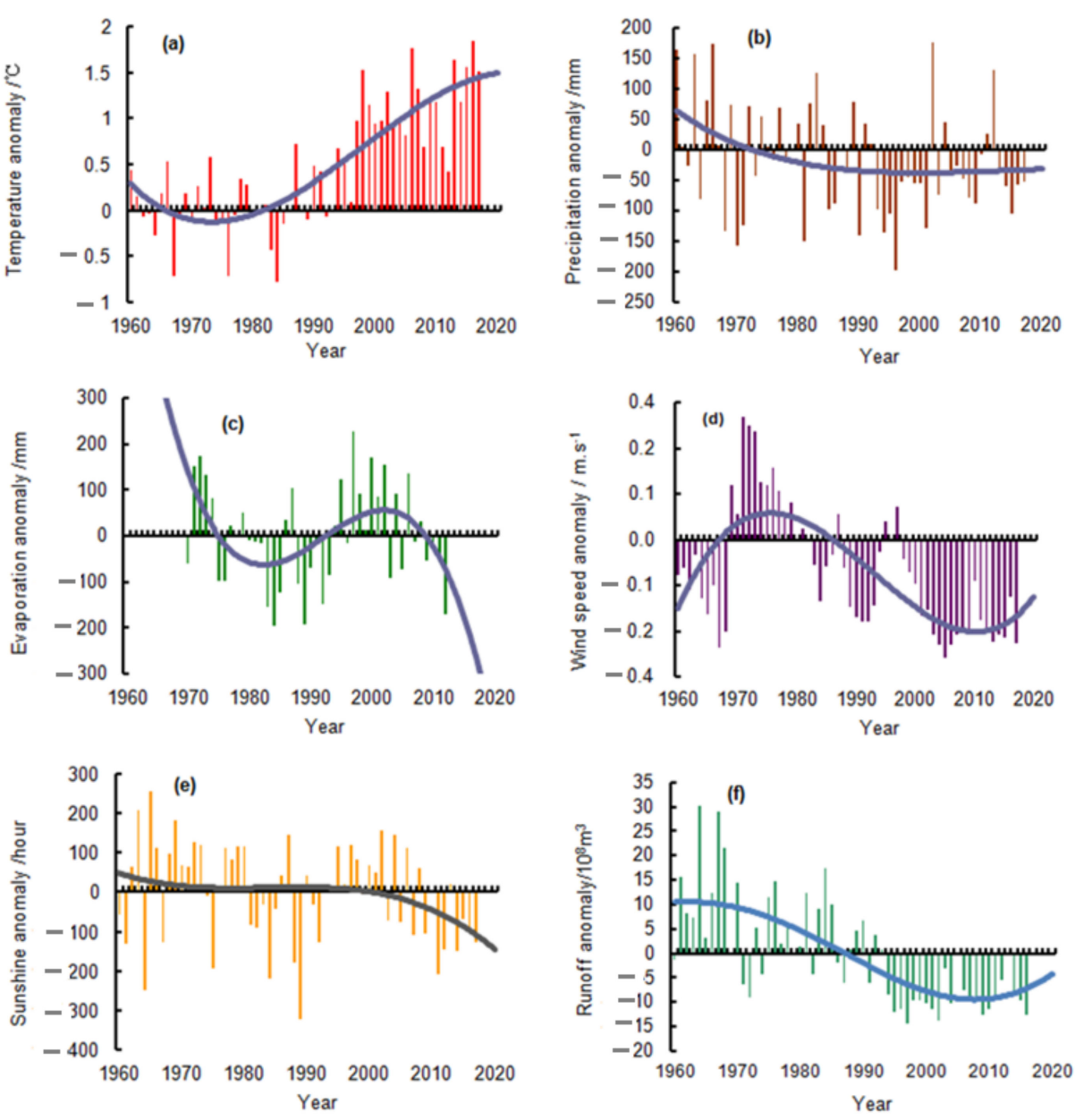

Figure 3. Change trend of meteorological and hydrological elements. (a) temperature, (b) precipitation, (c) evaporation, (d) wind speed, (e) sunshine, (f) runoff.

\subsection{Relationship between Climate and Runoff}

Runoff changes were affected by multiple climatic factors. Figure 4 shows the relationship between runoff and climate factors. It showed that, as temperature, sunshine hours and evaporation increased, runoff decreased, and there was a negative correlation between them. But as precipitation, relative humidity and wind velocity increased, runoff also increased, and there was a positive correlation between them. Except for wind speed, both other climatic factors and runoff showed a significant correlation, passing the 0.01 significance level test. The absolute value of the correlation coefficient between temperature, evaporation, precipitation and runoff reached above 0.6078 , indicating that these elements were the most important factors in reducing runoff. In arid and semi-wet areas, precipitation was the main form of runoff replenishment, and temperature has the greatest impact on runoff reduction, followed by evaporation, and other factors were relatively small. As can be seen, each meteorological element and runoff followed a certain linear or non-linear response law. 

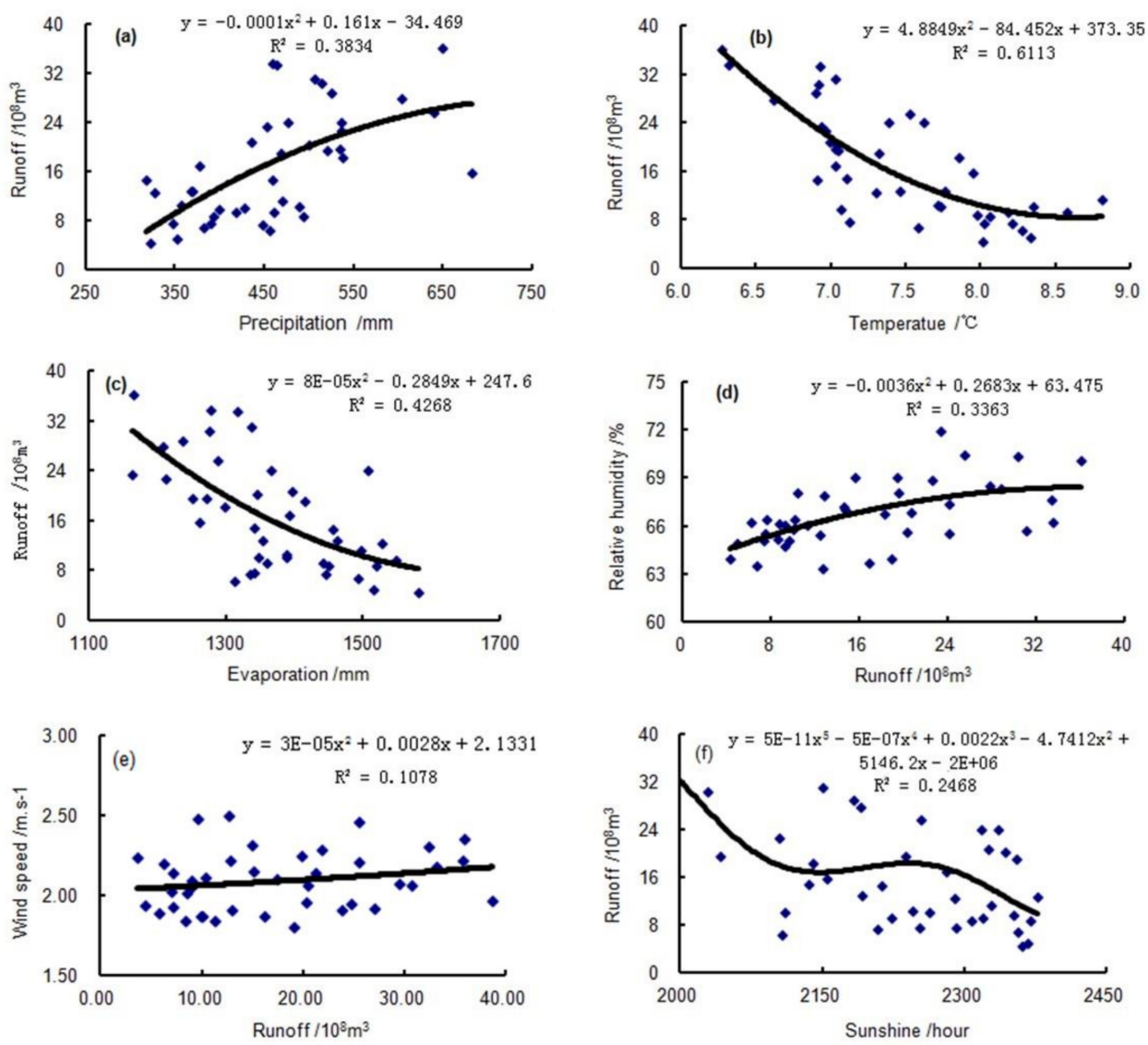

Figure 4. Relationship between runoff and climatic factors. (a) precipitation, (b) temperature, (c) evaporation, (d) relative humidity, (e) wind speed, (f) sunshine.

Therefore, the functional relationship between meteorological elements and runoff was established, as shown in Figure 4. Based on these relationships, it can be estimated that the runoff will decrease by $0.06 \mathrm{~mm}, 10.72 \mathrm{~mm}$ and $0.13 \mathrm{~mm}$ for the corresponding decrease of $1.0 \mathrm{~mm}$ precipitation, $1.0 \mathrm{~m} / \mathrm{s}$ wind velocity and $1.0 \%$ relative humidity, respectively, and decrease by $10.88 \mathrm{~mm}, 0.05 \mathrm{~mm}$ and $0.03 \mathrm{~mm}$ for the corresponding increase of $1.0{ }^{\circ} \mathrm{C}$ temperature, $1.0 \mathrm{~mm}$ evaporation and $1.0 \mathrm{~h}$ sunshine, respectively. As an important part in the hydrological cycle, the precipitation directly affected river runoff, while temperature indirectly affected river runoff mainly by influencing potential evaporation capacity. As the temperature rose and the precipitation decreased, the runoff decreased. Sunshine affected runoff by affecting temperature and evaporation. In general, the above relationship reflects the complexity of the interaction mechanism between various meteorological elements and runoff. Climatic elements affected runoff changes by the combined effects of positive and negative factors. Analysis shows that after 2000, the correlation coefficients between the main meteorological elements and runoff were generally weakened, which may be mainly due to the regulation and control of the large-scale water conservancy projects in the basin for the accumulation and replenishment of runoff. Changes in the underlying surface conditions such as basin topography, geological and geomorphic features, vegetation, etc., through the coupling of major meteorological elements, also increased the uncertainty of runoff formation.

\subsection{Sensitivity of Runoff to Climatic Factors and Human Activities}

Using standardized meteorological and hydrological factors, the coefficient sensitivity of runoff to climatic variation and human activities was calculated, as shown in Figure 5. It showed that the sensitivity of runoff changes to various factors in different areas significantly varied. In the SM1, SM2 and SM5 of the Weihe River Basin with poor geographical 
environment and less human activity, the elastic coefficients of runoff to temperature, sunshine hours, relative humidity, wind velocity and LUCC (i.e., land-use types area changes, including cultivated land, forest land, grassland, waters, industrial and mining land, and bare land, were used to assess the impact of land use on runoff) were smaller than those in SM3, SM4 and SM6, with intense human activity. The sensitivity of runoff to precipitation, temperature, evaporation, relative humidity, sunshine hours, wind velocity and LUCC was 1.27 4.17 (mean 2.38), -0.31 -1.12 (mean -0.75), 1.99 2.88 (mean 2.24), 0.84 1.7(mean 1.23), -0.11 -1.4 (mean -0.93), $0.31 \sim-0.93$ (mean -0.52) and -1.2 -3.8(mean -2.04), respectively. The multifactor comprehensive sensitivity of runoff to climatic factors and human activities was $25 \%$ greater than the sensitivity of single-factor sensitivity. The sensitivity of runoff to each factor can be ordered from high to low as follows: precipitation $>$ evaporation $>$ LUCC $>$ relative humidity $>$ sunshine hours $>$ temperature $>$ wind velocity, which showed that runoff has a higher response to precipitation, evaporation and LUCC. Precipitation and relative humidity positively drive runoff changes, while temperature, sunshine hours, wind velocity and LUCC negatively drive runoff changes. The increase of relative humidity reduced evapotranspiration in the watershed, reducing the loss of runoff. On the contrary, increasing sunshine hours, temperature and wind velocity led to a decrease of runoff. In addition, the increase of vegetation coverage on the underlying surface enhanced the function of soil and water conservation, resulting in a decrease in runoff. In the tributary basins of the Weihe River Basin, runoff was more sensitive to climate change and LUCC, while runoff in the mainstream of the Weihe River Basin, was poorly sensitive to climate and human activities. Generally, the relationship between meteorological elements and runoff followed a certain non-linear rule. When the watershed is disturbed by external factors, this response relationship of the hydrological cycle to climatic change will be changed, thereby affecting the change of river runoff by complex underlying surface conditions affecting the runoff generation and confluence of the watershed. These have led to a decrease in the sensitivity of runoff to climate and an increase in the sensitivity to human activities, indicating that the impact of human activities on runoff in the watershed was becoming more obvious.
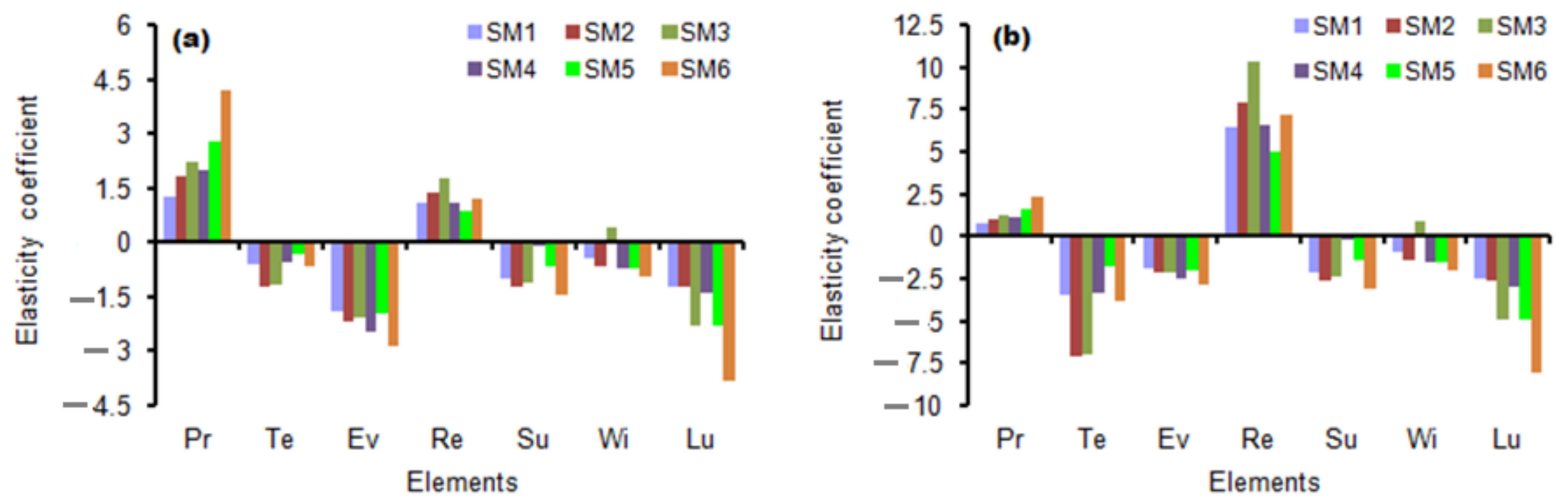

Figure 5. (a) Single-factor sensitivity estimates and (b) multifactor comprehensive sensitivity estimates of runoff to climatic factors and human activities. $\mathrm{Pr}, \mathrm{Te}, \mathrm{Ev}, \mathrm{Re}, \mathrm{Su}, \mathrm{Wi}$ and Lu represent precipitation, temperature, evaporation, relative humidity, sunshine hours, wind velocity and LUCC, respectively.

\subsection{Contribution of Climatic Variation and Human Activities to Runoff}

In the hydrological cycle, precipitation and evaporation were used to assess the contribution of climatic variation to runoff. The sliding $t$ test method was utilized to determine the meteorological and runoff inflection points. The significance test was performed as shown in Figure 6. It was found that the precipitation and runoff at each station had same abrupt points in 1970, 1985, 1993 and 1997. 

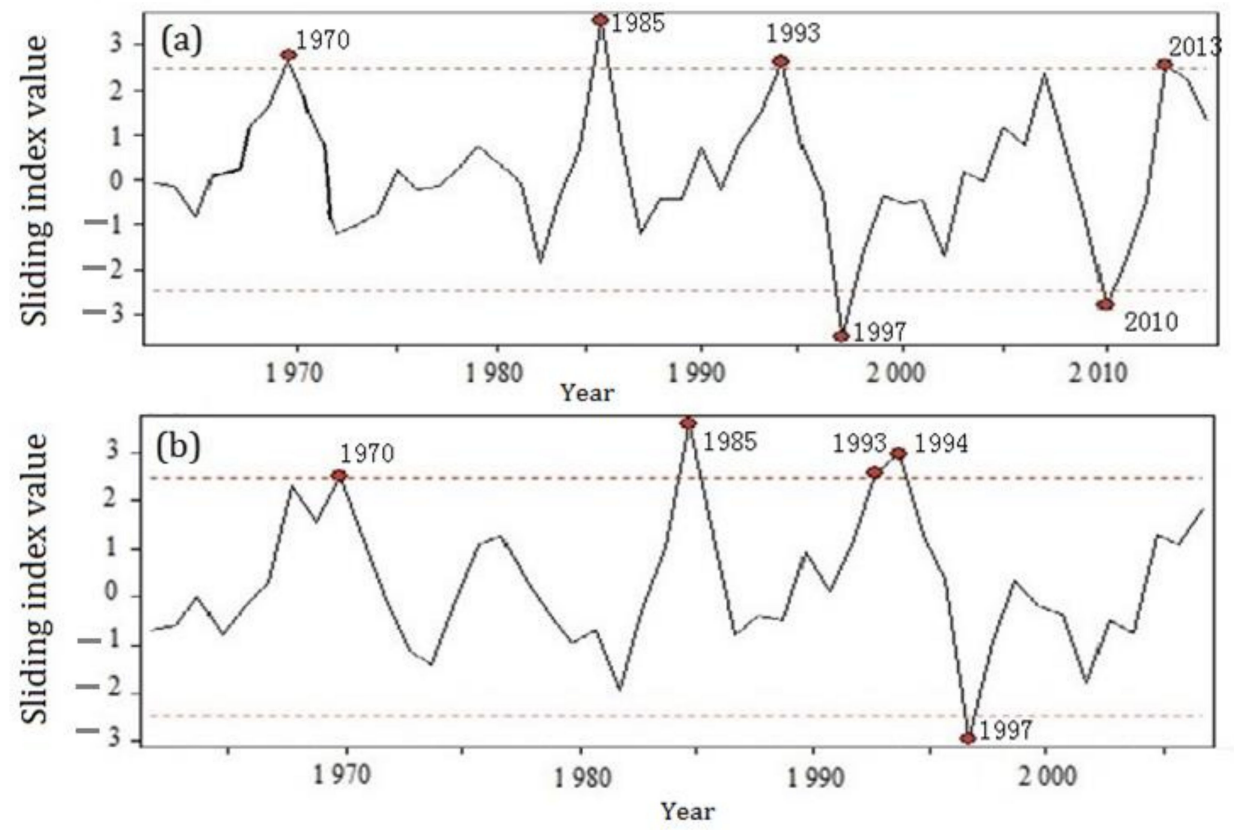

Figure 6. Sliding $t$ abrupt points test of (a) precipitation and (b) runoff.

As shown in Figure 7, the accumulated anomalies of mean precipitation and evaporation have increased or decreased in different periods. The double-accumulation curve of runoff and precipitation at each station showed obvious slope changes in 1970, 1985 and 1993, while the three years passed the abrupt test. Therefore, based on the common abrupt points, the changes in runoff can be divided into four periods, i.e., 1960-1970 (T1), 1971-1985 (T2), 1985-1993 (T3) and 1993-2017 (T4). In these four periods, the linear correlation coefficient was above 0.99 , which indicated that the determination of the mutation year was reliable to assess the contribution of climatic variation and human activities to runoff. The slopes and variable of runoff, precipitation and evaporation in the four periods were calculated, as shown in Table 2. Based on these slopes, the contributions of climatic variation and human activities to runoff in different periods were calculated, as shown in Table 3.

In the period of $\mathrm{T} 1$, the contribution of climatic variation to the reduction of runoff was above $54.83 \%$, and the contribution rate of human activities to runoff changes was $11.44-45.17 \%$. But in SM5, the contribution of climatic elements to runoff reached above $110.0 \%$. This may be because SM5 (Yimen) was located on the south side of the Weihe River, and rainfall was abundant, and the impact of human activities to hydrological cycle was smaller. In the period of T2, the influence of climatic variation on the reduction of runoff was above $14.76 \%$. The maximum contribution rate was above $91.19 \%$ in SM1 and SM2, while the minimum contribution rate was $14 \%$ in SM3. In the period of T3, the contribution of climatic variation to the reduction of runoff decreased below $42.59 \%$. At the same time, the impact of human activities on runoff increased. In SM2-SM5, the contribution of human activities to runoff reached above $57.41 \%$, but the contribution rate of human activities to runoff was only $0.92 \%$ in the SM1. In the period of T4, the contribution of human activities to the reduction of runoff increased by $64 \%$. Overall, from 1960 to 1985 , the contribution rate of climatic variation to the reduction of runoff was $68.3 \%$, while the contribution rate of human activities to the reduction of runoff was $31.7 \%$. After 1994, the contribution rate of climatic variation to runoff declined by less than $43 \%$, while the contribution of human activities to the runoff changes increased by above $57 \%$. In the entire basin, the average contribution rates of climatic variation and human activities to runoff changes were $22.3 \%$ and $77.6 \%$, respectively. In the watersheds, runoff was affected by the natural environment and human activities in different regions, resulting in different contribution rates. Due to the enhancement of soil and water conservation functions, and climate warming, as well as 
the reduction of precipitation, human activities have become the main factor causing the reduction of runoff, but the impact of climatic variation on runoff cannot be ignored.
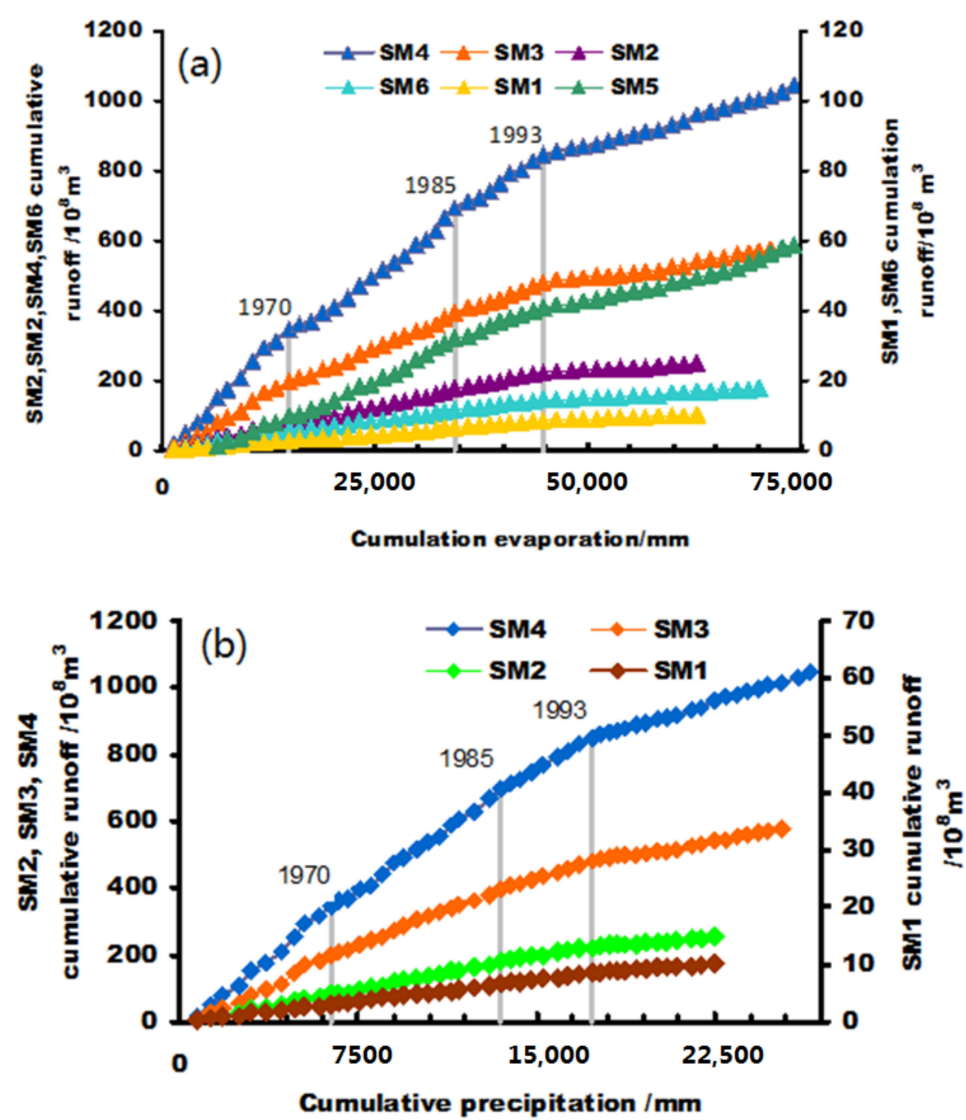

Figure 7. Relationship between cumulative actual runoff and (a) evaporation and (b) precipitation.

Table 2. Slope of cumulative precipitation, evaporation and runoff over time.

\begin{tabular}{|c|c|c|c|c|c|c|c|c|}
\hline \multirow{2}{*}{ Period } & \multirow{2}{*}{$\begin{array}{l}\text { Precipitation } \\
(\mathrm{mm})\end{array}$} & \multirow{2}{*}{$\begin{array}{l}\text { Evaporation } \\
\text { (mm) }\end{array}$} & \multicolumn{6}{|c|}{ Runoff $\left(10^{8} \mathrm{~m}^{3}\right)$} \\
\hline & & & SM1 & SM2 & SM3 & SM4 & SM5 & SM6 \\
\hline $\mathrm{T} 1$ & 692.17 & 1356.27 & 0.29 & 6.67 & 14.24 & 27.83 & 1.4 & 4.38 \\
\hline $\mathrm{T} 2$ & 564.52 & 978.72 & 0.24 & 6.57 & 13.34 & 23.14 & 1.25 & 2.42 \\
\hline T3 & 544.41 & 970.73 & 0.23 & 5.53 & 10.6 & 19.46 & 1.02 & 3.21 \\
\hline $\mathrm{T} 4$ & 511.05 & 1022.3 & 0.13 & 2.19 & 5.25 & 9.55 & 0.54 & 1.16 \\
\hline
\end{tabular}

Table 3. Contribution of (a) climatic variation and (b) human activities to runoff in different periods.

\begin{tabular}{ccccccccc}
\hline & \multicolumn{3}{c}{ Climatic Variation } & \multicolumn{5}{c}{ Human Activities } \\
\hline & T1 & T2 & T3 & T4 & T1 & T2 & T3 & T4 \\
\hline SM1 & 88.56 & 128.78 & 99.08 & 35.53 & 11.44 & -28.78 & 0.92 & 64.47 \\
SM2 & 78.75 & 91.19 & 18.18 & 20.53 & 21.25 & 8.81 & 81.82 & 79.47 \\
SM3 & 66.22 & 14.76 & 8.08 & 13.21 & 33.78 & 85.24 & 91.92 & 86.79 \\
SM4 & 67.17 & 41.25 & 18.47 & 11.40 & 32.83 & 58.75 & 81.53 & 88.60 \\
SM5 & 116.03 & 37.63 & -26.12 & 5.72 & -16.03 & 62.37 & 126.12 & 94.28 \\
SM6 & 54.83 & 46.65 & 42.59 & 32.02 & 45.17 & 53.35 & 57.41 & 67.98 \\
\hline
\end{tabular}

\subsection{Estimation of Future Runoff}

The IPCC Fourth Assessment Report states that the global average temperature will likely to increase by $1.1-6.4{ }^{\circ} \mathrm{C}$ at the end of the 21 st century under different greenhouse 
emission scenarios. Although climate variation can be regarded as a small disturbance, its hydrological effects cannot be ignored. Taking into account the uncertainty and accuracy of future climatic variation scenarios, this paper considered 30 possible climate scenarios, i.e., precipitation change of $\pm 20 \%, 0 \%$ and $\pm 10 \%$ while the temperature remains the same and rises by $0.5{ }^{\circ} \mathrm{C}, 1.0^{\circ} \mathrm{C}, 1.5^{\circ} \mathrm{C}, 2.0^{\circ} \mathrm{C}$ and $2.5^{\circ} \mathrm{C}$, to estimate the future changes of runoff. Figure 8 shows the relationship between future temperature, precipitation and runoff in the Weihe River Basin. The slope of the curve can characterize the degree of response of runoff to the changes in precipitation to a certain extent, and the distance between the curve groups represented the runoff changes caused by the difference in temperature changes. From Figure 8, it can be seen that, during the flood season (July to September), as the precipitation increased, the curve group tended to diverge, while the degree of divergence was greater than that of the annual curve group, indicating that, with the increase of precipitation, the impact of temperature changes on runoff became more significant. As the precipitation remained the same while the temperature increased by $1.0^{\circ} \mathrm{C}$, the runoff decreased by $13.3 \%$. As the temperature remained the same and the precipitation increased by $10 \%$ (decreased by $10 \%$ ), the runoff increased by $22.7 \%$ (decreased by $25.9 \%$ ). Under the scenario of precipitation declining, runoff changes during the flood season were about $1.4 \%$ smaller than the change in annual runoff. On the contrary, under the scenario of increased precipitation, the runoff change during the flood season was $2.3 \%$ greater than the change in annual runoff. It should be noted that, as temperature increased by $2.5^{\circ} \mathrm{C}$ and precipitation decreased by $20 \%$, runoff decreased by up to $59.8 \%$. In contrast, as temperature and precipitation both increased by $2.5^{\circ} \mathrm{C}$ and $20 \%$, runoff increased by up to $46.8 \%$. These indicated that the runoff in the arid and semi-arid regions of northwest China could have a stronger response to precipitation and temperature in the future. Climatic change may further aggravate the vulnerability of the water resources system. Therefore, it was of great significance to strengthen the adaptive management of the response of water resources to climate change, ensuring the safety of water resources.
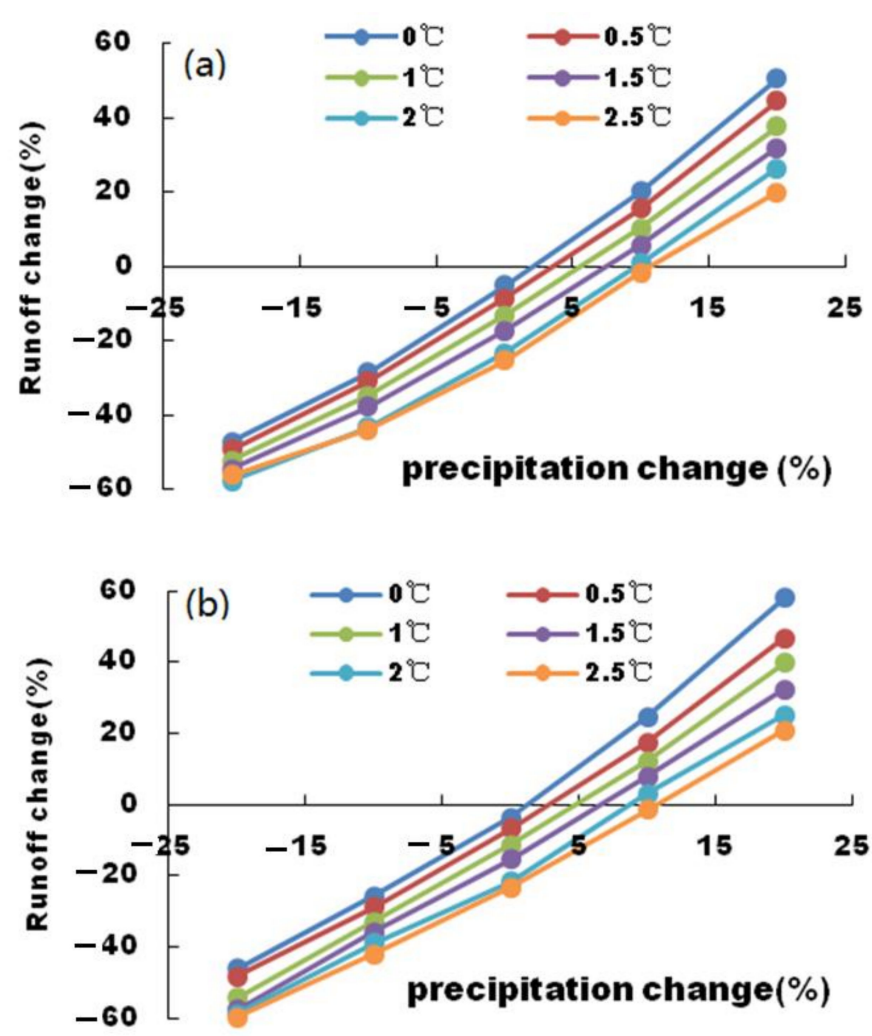

Figure 8. Variation of (a) annual runoff and (b) runoff in June, July and August under different climate scenarios in the future. 


\section{Discussion}

From the results, the temperature had an increasing trend over time, while precipitation, wind velocity, sunshine hours, evaporation, relative humidity and runoff decreased. These findings were mostly consistent with the climate trends reported in literature [29]. However, the changing rate of the meteorological factors in this study was higher than that of the existing research [30]. Among all meteorological elements, evaporation was closely related to temperature, wind velocity, sunshine hours and LUCC. The increase in temperature led to the increase in evaporation; however, the decrease in wind velocity and sunshine hours led to the increase in evaporation. Moreover, the changing rate of the meteorological factors was higher than that of the existing research [31-33]. These differences may be caused by data resolution and time scale. Overall, this study further revealed the changing trends of climate elements and runoff in the Weihe basin of western China. Under the background of global warming, the temperature in the Weihe River Basin is also increasing, but evaporation is decreasing. It was considered that the decrease of sunshine hours and wind velocity could be the primary reason for the decrease of evaporation. Although the temperature rose, the regional evaporation was reduced, and the hydrological cycle slowed down. In addition, the study also believed that the decreased runoff was due to the decrease in precipitation and relative humidity, as well as the increase in temperature. The study suggested that the climate warming would intensify the water-cycle process and drive changes of hydrological factors. It should be noted that the increasing temperature, decreasing sunshine and wind velocity resulted in the runoff reduction. The underlying parameters characterized watershed characteristics of vegetation and soil, and the parameters of vegetation coverage area in the watershed increased, while the vegetation's function of maintaining soil and water was enhanced, leading to a decrease in runoff. The results were basically consistent with the existing studies [34-36]. Some differences were due to the difference in the comparison period.

At present, the purpose of most climate sensitivity studies is to understand the influence of changes in precipitation on watershed runoff. Based on Budyko's hypothetical water-heat coupling balance equation, this paper considered the impact of multiple meteorological factors and LUCC on runoff. The modified Penman-Monteith evaporation model was employed to derive the elastic coefficients of various factors on runoff. Compared with the existing research $[37,38]$, the reliability of the results has been improved, which could better explain the response intensity of hydrological cycle to climate change and human activities. This study also found that in the mainstream areas with high population density and urbanization development, human activities significantly influenced the reduction of runoff, while, in the natural environment, climate warming and precipitation had a greater impact on runoff. Previous research in different climatic regions in China suggested that the watershed runoff in arid and semi-arid areas in north of the Yellow River was most sensitive to climatic variation, followed by central and southern China semi-humid and humid regions $[39,40]$. The studies on US MOPEX watershed believed that the runoff has significantly different response to precipitation in the eastern and western basins of the United States [41], which also indicated that the sensitivity of runoff to climatic variation in river basin was spatially different. This study believed that in watersheds with large amount of precipitation, climate was the main factor to cause the runoff increase, while the runoff turned back to respond strongly to climate change. Human activities were the main factor to result in reduction of runoff in areas with little precipitation, while the runoff was more resilient to human activities.

Decomposing the influences of climatic variation and human activities on runoff contributes to understand the driving mechanism of the variation in water cycle. Human activities, including underlying surface changes, reservoir construction, land use and socio-economic development (population, GDP), can influence the regional water-cycle process, which have an impact on river basin runoff. The slope model established in this study has the same calculation accuracy as other complex models [42,43]. It can better decompose the influence process of climatic variation and human activities on runoff in 
different periods. Recently, the emphasis on the climatic variation and the improvement of the natural environment has reduced the influence of human activities on the decreasing trend of runoff $[44,45]$. However, human activities usually affect land use, vegetation cover, etc., and are still the main factors affecting the variation of runoff. The study compared the four hydrological stations and showed that human activities contributed more significantly to the reduction of runoff in Linjiacun, Beidao and Wushan stations. It should be noted that the results at Weiyuan station were obviously different than the other three stations, especially in T2, and the contribution rate was significantly greater than the other three stations. Although the contribution of human activities to the variation of runoff at Weiyuan Station has shown an increasing trend, it is still the lowest among the four stations. This was related to the fragile geographical environment of Weihe River and economic development level. This study has found that before 1985, natural climatic variation contributed to more than $38 \%$ reduction of runoff. After 1985, climatic influence decreased, while the human activities contributed to more than $57 \%$ of runoff. It is therefore believed that human activities had much more significant influences on watershed runoff than climatic variation, and the contribution rate of human activities was mostly above 50\% in Weihe River Basin. These indicate that the climatic variation contributed more significantly to the reduction of runoff than human activities at different stations in different periods. The contribution rate of human activities to the reduction of runoff has increased, and the contribution of climate change to the reduction of runoff has weakened. However, the impact of climate change on the hydrological cycle was as important as the impact of human activities on the hydrological cycle. The existing research $[46,47]$ showed that runoff in China will be reduced by $45 \%$ in the future. In this study, based on the climate scenario, the future runoff assessment indicates that the runoff of the Weihe River Basin will be reduced by 56\%, indicating that the future water-shortage problem of the Weihe River Basin will be more serious. Since 1995, the impact of human activities on the environment was far greater than the changes in nature itself. Human activities have changed the relationship between the natural climate and the hydrological cycle by changing the underlying surface conditions. The construction of water-conservancy facilities redistributed runoff in time and space, thereby affecting the regional water cycle process. Various land-use types in the basin have different water cycles and hydrological effects. For example, the decrease in the area of grassland and water bodies and the decrease in soil water content reduced the ability to regulate runoff in the watershed; the increase in urban land area led to an increase in surface runoff and a decrease in infiltration; the increase in arable land changed water distribution in the watershed, and at the same time, indirectly affected other land-use methods in the watershed, thereby causing the change of runoff by changing the runoff generation and convergence conditions of the underlying surface.

Overall, we have quantitatively analyzed the sensitivity and response intensity of runoff to climate change and human activities. This study has also decomposed the contribution rate of climate change and human activities to runoff and revealed the vulnerability of water resources to climate change in the future. The established models were suitable for evaluating the response of regional runoff to climate change and human activities. The models have certain applicability to the Weihe River Basin. It is believed that climate warming intensified the water cycle process and could drive the changes in precipitation, evaporation and runoff hydrological factors, thus affecting the regional water balance and water distribution. The influence of human activities on hydrology was mainly through the utilization of land use, soil and water conservation, rainwater storage and other methods to alter the underlying surface of the watershed, which led to changes in runoff regimes. Generally, in areas with low human activities, natural climate change was the main factor affecting changes in hydrological processes. Precipitation increases runoff, while temperature has a dissipation effect on water resources. In the future, when precipitation increases and temperature rises, runoff will increase; when temperature rises and precipitation decreases, runoff will decrease significantly. Compared with the existing literature, the study is innovative in the analysis method of quantitatively identifying the impact of climate 
change and human activities on the hydrological cycle. However, the mechanism of human activities on runoff is more complex. Therefore, the quantitative decomposition of various human activity factors on runoff needs to be further studied.

\section{Conclusions}

This paper systematically assessed the changing trends of climate elements and hydrological elements and the sensitivity of runoff to climate and human activities, and quantitatively revealed the contribution rate of climate change and human activities to the reduction of runoff. The following conclusions can be obtained:

The temperature has a significant increasing trend, while precipitation, evaporation, runoff, relative humidity, sunshine hours and wind speed have a decreasing trend. Precipitation and relative humidity have a non-linear positive driving effect on runoff, while temperature, evaporation, sunshine hours, wind velocity and LUCC have non-linearly negatively driven variation in runoff. The sensitivity of runoff to each climate element can be ordered as follows: precipitation $>$ evaporation $>$ LUCC $>$ relative humidity $>$ sunshine hours $>$ temperature $>$ wind velocity. In addition, the sensitivity of runoff to climatic variation and human activities was spatially different. In the tributary basins of the Weihe River Basin, runoff was more sensitive to precipitation, evaporation and LUCC, while runoff in the mainstream of the Weihe River Basin was poorly sensitive to climate and human activities. In areas with strong human activities, the sensitivity of runoff to climatic change weakens, and the elasticity of runoff to underlying surface parameters increased.

The contribution rates of climatic variation and human activities to runoff showed that, before 1985, the climatic variation had greater influence on runoff reduction than human activities. After 1985, the contribution rate of climatic variation to runoff decreased, and the influence of human activities on runoff increased. The contribution rates of average climatic variation and human activities to the variation in runoff reached $22.3 \%$ and $77.6 \%$, respectively. The impact of human activities on runoff gradually increased in the semi-arid northwest.

In areas with a geographically fragile environment and intense human activities, the influence of human activities on runoff was the main factor. It was believed that climate variation drastically drove the water cycle of precipitation and evaporation and affected regional water balance and water distribution, while human activities changed the hydrological process by influencing the flow generation and confluence of the underlying surface. Under 30 assumed climatic scenarios, the evaluation of runoff showed that the runoff in the Weihe River Basin will be significantly reduced in the future. During the flood season, the runoff reduction has a stronger response to precipitation and temperature, which can cause serious water-resource problems. This study provides a basis for the quantitative assessment of the influence of climatic variation and human activities on variations in regional runoff.

Author Contributions: Y.L. conceived and designed the study; K.Y. and Y.Z. analyzed the data; J.B. contributed to data preparation, figures and tables; Y.L. wrote the manuscript; Y.L., Y.Z., K.Y. and J.B. contributed to revising and improving the manuscript. All authors have read and agreed to the published version of the manuscript.

Funding: This study was supported by the National Natural Science Foundation Key Project of China (No.41771048), National Social Science Foundation of China (No.15XZZ012) and the Key Project of Baoji University of Arts and Sciences (No. ZK16061).

Institutional Review Board Statement: Not applicable.

Informed Consent Statement: Not applicable.

Data Availability Statement: Not applicable.

Conflicts of Interest: The authors declare no conflict of interest. 


\section{References}

1. Andréassian, V.; Coron, L.; Lerat, J.; Le Moine, N. Climate elasticity of stream flow revisted: An elasticity index based on long -term hydro meteorological records. Hydrol. Earth Syst. Sci. Discuss. 2016, 12, 3645-3679. [CrossRef]

2. Song, X.M.; Zuang, J.Y.; Zhan, C.S.; Liu, C.Z. Review for impacts of climate change and human activities on water cycle. J. Hydraul. Eng. 2013, 44, 779-790. (In Chinese with English abstract)

3. Liu, Y.G.; Wang, N.L.; Zhang, J.H.; Wang, L.G. Climate change and its impacts on mountain glaciers during 1960-2017 in western China. J. Arid Land 2019, 1, 537-550. [CrossRef]

4. Wang, G.Q.; Zhang, J.Y.; Liu, J.F.; Jin, J.L.; Liu, C.S. The sensitivity of runoff to climate change in different climatic regions in China. Adv. Water Sci. 2011, 22, 307-314. (In Chinese with English abstract)

5. Yang, Y.; Cui, Y.L.; Lou, Y.F.; Lyu, X.; Traore, S.; Khan, K.; Wang, W.G. Short-term forecasting of daily reference evapotranspiration using the penman-Monteith mode land public weather forecasts. Agric. Water Manag. Forecast. 2016, 177, 329-339. [CrossRef]

6. Liu, J.Y.; Zhang, Q.; Gu, X.H. Evaluation of ecological flow with considerations of hydrological alterations in the Poyang Lake basin. Acta Ecol. Sin. 2015, 35, 5477-5485. (In Chinese with English abstract)

7. Piao, S.; Ciais, P.; Huang, Y.; Shen, Z.; Peng, S.; Li, J.; Zhou, L.; Liu, H.; Ma, Y.; Ding, Y.; et al. The impacts of climate change on water resources and agriculture in China. Nature 2010, 467, 43-51. [CrossRef]

8. Liu, Y.G.; Guo, Z.M.; Zhou, Q.; Wu, X.B.; He, J.Q. The climate characteristics of the first date of $\leq 0{ }^{\circ} \mathrm{C}$ temperature in East China. Arct. Antarct. Alp. Res. 2015, 47, 83-93. [CrossRef]

9. Carmona, A.M.; Renner, M.; Kleidon, A.; Germán, P. Uncertainty of runoff sensitivity to climate change in the Amazon River basin. Ann. N. Y. Acad. Sci. 2020, 1504, 76-94. [CrossRef]

10. Wang, S.J.; Li, L.; Yan, M. The contributions of climate change and human activities to the runoff yield changes in the middle Yellow River Basin. Geogr. Res. 2013, 32, 395-402.

11. Yao, J.Q.; Yang, Q.; Mao, W.Y.; Xu, X.B.; Liu, Z.H. Evaluation of the impacts of climate change and human activities on the hydrological environment in Central Asia. J. Glaciol. Geocryol. 2016, 38, 222-230. (In Chinese with English abstract)

12. Yang, H.; Qi, J.; Xu, X.Y.; Yang, D.W.; Lv, H.F. The regional variation in climate elasticity and climate contribution to runoff across china. J. Hydrol. 2014, 517, 607-616. [CrossRef]

13. Yang, H.; Yang, D. Derivation of climate elasticity of runoff to assess the effects of climate change on annual runoff. Water Resour. Res. 2011, 47. [CrossRef]

14. Jiang, C.; Xiong, L.; Wang, D.; Liu, P.; Guo, S.L.; Xu, C.Y. Separating the impacts of climate change and human activities on runoff using the Budyko-type equations with time-varying parameters. J. Hydrol. 2015, 522, 326-338. [CrossRef]

15. Liang, W.; Bai, D.; Wang, F.Y.; Fu, B.J.; Yan, J.P.; Wang, S.; Yang, Y.T.; Feng, M.Q. Quantifying the impacts of climate change and ecological restoration on streamflow changes based on a Budyko hydrological model in China's Loess Plateau. Water Resour. Res. 2015, 51, 6500-6519. [CrossRef]

16. Chebana, F.; Ouarda, T.B.M.J.; Duong, T.C. Testing for multivariate trends in hydrologic frequency analysis. J. Hydrol. 2013, 486, 519-530. [CrossRef]

17. Yin, G.D.; Wang, X.; Zhang, X.; Fu, Y.S.; Hu, Q.H. InVEST Model-Based Estimation of Water Yield in North China and Its Sensitivities to Climate Variables. Water 2020, 12, 1692. [CrossRef]

18. Gao, G.; Fu, B.; Wang, S.; Liang, W.; Jiang, X.H. Determining the hydrological responses to climate variability and land use/cover change in the loess plateau with the budyko framework. Sci. Total Environ. 2016, 557, 331-342. [CrossRef]

19. Ma, C.K.; Su, L.; Liu, S.Y.; Shao, M.A.; Luo, Y. Impact of climate change on the streamflow in the glacierized Chu River Basin, Central Asia. J. Arid Land 2015, 7, 501-513. [CrossRef]

20. Guo, Q.L.; Yang, Y.S.; Li, J.L.; Wang, X.Y. Impact Assessment of Climate Change and Human Activities on Runoff Variation in Coal Mining Watershed, NW China. Water Resour. 2019, 46, 871-882. [CrossRef]

21. Hu, Z.; Zhang, C.; Hu, Q.; Tian, H. Temperature changes in Central Asia from 1979 to 2011 based on multiple datasets. J. Clim. 2014, 27, 1143-1167. [CrossRef]

22. Wang, G.Q.; Zhang, J.Y.; He, R.M.; Liu, C.S.; Ma, T.; Bao, Z.X.; Liu, Y.L. Runoff sensitivity to climate change for hydro-climatically different catchments in China. Stoch. Environ. Res. Risk Assess. 2017, 31, 1011-1021. [CrossRef]

23. Kong, D.X.; Miao, C.Y.; Wu, J.W. Impact assessment of climate change and human activities on net runoff in the Yellow River basin from 1951 to 2012. Ecol. Eng. 2016, 91, 566-573. [CrossRef]

24. IPCC. Climate Change 2007: Synthesis Report; Cambridge University Press: Cambridge, UK, 2007.

25. Budyko, M.I. Climate and Life; Academic Press: San Diego, CA, USA, 1974; p. 322.

26. Liu, C.; Zhang, D. Temporal and spatial change analysis of the sensitivity of potential evapotranspiration to meteorological influencing factors in China. Acta Geogr. Sin. 2011, 66, 579-588. (In Chinese with English abstract)

27. Roderick, M.L.; Rotstayn, L.D.; Farquhar, G.D.; Hobbins, M.T. On the attribution of changing pan evaporation. Geophys. Res. Lett. 2007, 34, 251-270. [CrossRef]

28. Liu, Y.G.; Wang, S.X.; Wang, Y.; Hu, H.N. Evaluation of potential evapotranspiration in the Weihe River Basin based on statistical downscaling. IOP Conf. Ser. Earth Environ. Sci. 2018, 191, 012025. [CrossRef]

29. Markovich, K.H.; Maxwell, R.M.; Fogg, G.E. Hydrogeological response to climate change in alpine hill slopes. Hydrol. Process 2016, 30, 3126-3138. [CrossRef] 
30. Liu, Y.G.; Zhang, J.H.; Wang, S.X.; Wang, Y.; Zhao, A.L. Protection Assessment of Environmental Carrying Capacity Using Principal Component Analysis. J. Geosci. Environ. Prot. 2018, 6, 54-65. [CrossRef]

31. Li, H.; Zhang, Y.; Vaze, J.; Wang, B.D. Separating effects of vegetation change and climate variability using hydrological modelling and sensitivity-based approaches. J. Hydrol. 2012, 420, 403-418. [CrossRef]

32. Wang, W.; Shao, Q.; Yang, T.; Yang, T.; Peng, S.Z.; Xing, W.Q.; Sun, F.C.; Luo, Y.F. Quantitative assessment of the impact of climate variability and human activities on runoff changes: A case study in four catchments of the Haihe River basin, China. Hydrol. Process 2013, 27, 1158-1174. [CrossRef]

33. Ren, L.; Xue, L.Q.; Liu, Y.H.; Shi, J.; Han, Q.; Yi, P.F. Study on variations in climatic variables and their influence on runoff in the Manas Rive Basin, China. Water 2017, 9, 258. [CrossRef]

34. Bao, Z.X.; Zhang, J.Y.; Wang, G.Q.; Fu, G.; He, R.; Ya, X.; Jin, J.; Liu, Y.; Zhang, A. Attribution for decreasing streamflow of the Haihe River basin, northern China:Climate variability or human activities. J. Hydrol. 2012, 460, 117-129. [CrossRef]

35. Dong, L.H.; Xiong, L.H.; Yu, K.X.; Li, S. Research advances in effects of climate change and human activities on hydrology. Adv. Water Sci. 2012, 23, 278-285. (In Chinese with English abstract)

36. Xie, Y.; Li, X.; Wang, H. Spatio-temporal variation analysis of hydrochemical characteristics in the Luanhe River Basin, China. Water Sci. Technol. 2013, 67, 1332-1338. [CrossRef] [PubMed]

37. Liu, J.Y.; Zuang, Q.; Chen, X.; Gu, X.H. Quantitative evaluations of human- and climate-induced impacts on hydrological processes of China. Acta Geogr. Sin. 2016, 71, 1875-1885. (In Chinese with English abstract)

38. Barnett, T.P.; Pierce, D.W.; Hidalgo, H.G.; Bonfils, C.; Santer, B.D. Human-induced changes in the hydrology of the western United States. Science 2008, 319, 1080-1083. [CrossRef]

39. Wang, G.S.; Xia, J.; Chen, J. Quantification of effects of climate variations and human activities on runoff by a monthly water balance model: A case study of the Chaobai River basin in northerm China. Water Resour. Res. 2009, 45, 466-477. [CrossRef]

40. Tan, X.; Gan, T.Y. Contribution of human and climate change impacts to changes in streamflow of Canada. Sci. Rep. 2015, 5, 17767. [CrossRef]

41. Konapala, G.; Mishra, A.K. Three-parameter based streamflow elasticity model: Application to MOPEX basins the USA at annual and seasonal scales. Hydrol. Earth Syst. Sci. Discuss. 2016, 20, 2545-2556. [CrossRef]

42. Guo, D.L.; Westra, S.; Maier, H.R. Impact of evapotranspiration process representation on runoff projections from conceptual rainfall-Runoff models. Water Resour. Res. 2017, 53, 435-454. [CrossRef]

43. Jia, J.; Jiang, L.H. The impact of climate change and human activities on the runoff in the source area of the Weihe River in the past 30 years. Groundwater 2017, 39, 130-133.

44. Wang, X.J.; Jiang, R.G.; Xie, J.C.; Zhu, J.W.; Wang, Y.M. Analysis of change trend and sudden change of Weihe River runoff. J. Water Resour. Water Transp. Eng. 2019, 2, 33-40. (In Chinese with English abstract)

45. Yang, S.Y.; Jiang, R.G.; Xie, J.C.; Wang, Y.P.; Wang, Y.M. Study on the characteristics and attribution of runoff changes in the upper reaches of the Weihe River. J. Water Resour. Water Eng. 2019, 30, 37-42.

46. Ge, Z.N.; Hao, J.; Ju, Q.; Dong, X.T.; Hao, Z.C. Impact of land use changes on runoff in the Weihe River Basin. Yell. River 2020, 42, 7-12. (In Chinese with English abstract)

47. Dong, W.; Cui, B.S.; Liu, Z.H.; Zhang, K.J. Relative effects of human activities and climate change on the river runoff in an arid basin in northwest China. Hydrol. Processes 2014, 28, 4854-4864. [CrossRef] 